\title{
Count per Minute
}

National Cancer Institute

\section{Source}

National Cancer Institute. Count per Minute. NCI Thesaurus. Code C73688.

A unit of frequency expressed as a number of events per minute. 